УДК 632.928

\title{
К ВОПРОСУ ОБ ИЗУЧЕНИИ ХИМИЧЕСКОЙ СТРУКТУРЫ И ЛЕЧЕБНЫХ СВОЙСТВ INONOTUS OBLIQUUS (PERS.) PIL.
}

\author{
() М.Э. Баландайкин
}

Ульяновский государственный университет, ул. Л. Толстого, 42, Ульяновск, 432017, (Россия), e-mail: 131119892007@rambler.ru

Осуществляется обзор новых литературных данных, касающихся широко обсуждаемых сегодня проблем в научном мире по развитию представлений о характере строения и применения стерильных наростов гриба Inonotus obliquus (Pers.) Pil., именуемых чагой.

Ключевые слова: иммуномодулирующая, антиканцерогенная и антиоксидантная активность, Inonotus obliquus (Pers.) Pil. forma sterilis (Van.) Nikol.

Эмпирические поиски средств для лечения больных с раком гетерогенной этиологии ведутся на протяжении столетий. Мимо этого грозного заболевания не прошла и народная медицина, которая широко использует различные вещества природного происхождения - растительные, минеральные и др. Опыт народной медицины, проверенный на десятках поколений больных, дал здравоохранению ряд ценных лекарственных растений, используемых в производстве различных препаратов.

Одним из видов природного сырья, издавна применяющегося в народной медицине для лечения больных с желудочно-кишечными заболеваниями и раком различной локализации, являются наросты на березе, известные под названием чага (Inonotus obliquus (Pers.) Pil. forma sterilis (Van.) Nikol.) [16]. Способы применения ее в качестве лекарственного средства были описаны еще в трудах знаменитого средневекового врача Абу Али ибн Сины (Авиценны). Но только начиная со второй половины XX в. тысячелетний опыт народный медицины в борьбе с раком послужил стимулом к изучению фармакологически активных соединений гриба. Исследования свойств чаги, осуществленные профессорами П.А. Якимовым и И.К. Булатовым, привели к введению в официнальную медицину экстракта березового гриба [2]. После этого с каждым годом заметно увеличивалось число ученых, которые занимались изучением не только уже известных науке лечебных свойств I. obliquus, но и делали оригинальные открытия.

Учитывая тот факт, что все основные новаторские идеи так или иначе проходят жесточайшую селекцию временем, а также интеграцию отраслей наук и совершенствование их методологического аппарата, уместным окажется остановить внимание на открытиях в области химии I. obliquus и применения чаги в медицине, осуществленных за последнее время.

В своей монографии М.Я. Шашкина, П.Н. Шашкин, А.В. Сергеев и Л.К. Горяйнова [20] дают подробное описание химии бесплодных наростов и особенностей использования препаратов на основе чаги в лечебной и профилактической практике, где приводится анализ собственных экспериментально полученных данных по их химическому составу и обзор литературных данных за последний полувековой отрезок времени по препаратам, разработанным на основе чаги.

М.А. Сысоевой с соавторами проведены комплексные исследования золя водного извлечения чаги [4-9; 18], осуществлена сравнительная характеристика антиоксидантной активности водных и спиртовых извлечений чаги [17], произведено разделение водных извлечений чаги с использованием этилацетата [11-14], предложены методы по повышению антиоксидантной активности водных извлечений и меланинов чаги [10]. В частности, показано, что при обработке водных извлечений чаги водными растворами гиперраз-

Баландайкин Михаил Эдуардович - аспирант, e-mail: 131119892007@ rambler.ru ветвленных полимеров Boltorn Н марок Н30 и Н40 происходит изменение размеров частиц меланина, и, как следствие этого, возрастает антиоксидантная ак- 
тивность водных извлечений и меланинов из чаги в 2-4 раза [10]. На антиоксидантную активность спиртовых экстрактов из шрота чаги мало влияет сырье (шрот), взятое на экстракцию, и она в 1,5 раза выше, чем у водных извлечений из чаги [17]. Средний радиус мицелл полифенолоксикарбонового комплекса коллоидных систем водных извлечений чаги составляет 60-160 нм (при обработке водного извлечения чаги петролейным эфиром, этилацетатом и хлороформом радиус еще меньше) $[5,6]$. По результатам исследований авторов, полифенолоксикарбоновый комплекс может состоять как из двух, так и из трех типов полимерных структур с разной молекулярной подвижностью; водные экстракты чаги, полученные различными способами и на разном сырье, имеют примерно одинаковый состав и активность, но отличаются степенью связанности компонентов [4]. В составе водных экстрактов в свободном или слабосвязанном состоянии М.А. Сысоева с соавторами обнаружили фенольные соединения, углеводы, липиды. Из последних преобладают нейтральные липиды: стерины и их эфиры, ненасыщенные жирные кислоты, витамин К, кофермент Q. Полярные липиды представлены фосфолипидами и гликолипидами [8]. В этилацетатном экстракте обнаружены фенолкарбоновые кислоты, простые фенолы, флавоноиды, иридоиды и азулены [14].

J.H. Lee и M.J. Lee получили сигмоидальные изотермы сорбции влаги грибом при диапазоне температур 20-50 ${ }^{\circ} \mathrm{C}$ [48]. В работе [49] ими было исследовано содержание равновесной влажности грибного порошка чаги в зависимости от величины частиц. Достоверно установлено, что содержание равновесной влажности намного больше в образцах, состоявших из частиц меньшей величины. Также J.H. Lee, M.J. Lee и E.J. Seog изучили воздействие методов сушки на физико-химические свойства грибного порошка чаги: сушка при температуре ниже нуля градусов привела к уменьшению частиц порошка и увеличению его пористости, по сравнению с сушкой горячим воздухом и вакуумной сушкой [50].

Т.А. Кукулянская с соавторами установили различия в химической структуре и биологической активности меланинов чаги, произрастающей в естественных условиях и выращенной в культуре [56]. В.Г. Бабицкая с соавторами исследовали эндо- и экзомеланины I. obliquus [1]. Изучение их состава показало, что по содержанию в них углерода, азота, водорода, а также по количеству метотоксильных, алифатических и фенольных групп они близки между собой. По содержанию же карбоксильных групп несколько отличаются: у экзомеланина - 0,5\%, а у эндомеланина - 1,4\%. Гидролизаты меланиновых пигментов содержали 17 аминокислот: лизин, гистидин, аргинин, аспарагиновую и глутаминовую кислоты, треонин, серин, пролин, глицин, аланин, валин, цистин, метионин, изолейцин, лейцин, тирозин, фенилаланин. Сумма их в экзомеланине I. obliquus составила $36,40 \%$, в эндомеланине - 32,20. Молекулярная масса меланинов - 35-50 кДа.

Регулирующее воздействие света на биосинтез полифенолов чагой и их антиоксидантную активность установили W. Zheng et al. [54]. Причем освещение дневным светом замедляло биосинтез и снижало антиоксидантную активность, по сравнению с ростом гриба при синем и красном спектре, и тем более в темноте. В работе [58] W. Zheng et al. провели исследование по глубинному культивированию Inonotus obliquus и Phellinus punctatus. Совместное культивирование этих грибов привело не только к снижению количества биомассы мицелия чаги, но и к увеличению фенольных производных, меланинов и тритерпеноидов, что объясняется конкуренцией грибов за питательные вещества и изменением их метаболизма.

В последнее время учеными обнаружено много новых химических соединений I. obliquus из числа тритерпенов - T. Nakata et al. [63], S. Nakamura et al. [23], S. Taji, N. Handa, T. Yamada и R. Tanaka [40; 64], Y. Shin, Y. Tamai и M. Terazawa [61]; полифенолов - I.-K. Lee et al. [53]. W.F. Zheng et al. показали различие в составе стеролов, выделенных из природного мицелия, выращенного в культуре, объяснив это воздействиями окружающей природной среды на рост гриба, такими как температура, ультрафиолетовое излучение, радиация и др., которые способны замедлять ферментативную активность синтеза эргостерола (18,5\% против 82,2\% в культуре) и тем самым ингибировать биосинтез стеролов [62]. Летучие вещества чаги изучали N. Ayoub, D. Lass и W. Schultze [31]. Они впервые определили содержание в ней некоторых сесквитерпенов : $\alpha$-сантален, эпихлоргидрин - $\beta$-сантален, фотосанталол и др.

Рядом исследователей также указано на несоответствие результатов измерений содержания отдельных веществ в чаге, полученных различными аналитическими методами. Так, например, в этом отношении весьма показательна работа S.J. Rhee et al. относительно вариации результатов по определению концентрации щелочно-растворимого $\beta$-люкана в стерильной форме гриба альтернативными способами его идентификации [22].

Достаточно много исследований, касающихся возможностей использования I. obliquus в медицине, проведено как отечественными, так и зарубежными учеными.

Иммуномодулирующую активность водной вытяжки чаги на клетках костного мозга подтвердил Yeon-Ran Kim [47]. Y.O. Kim et al. провели исследование эндополисахаридов I. obliquus, выделенных из 
мицелия, выращенного в культуре, и показали, что они обладают иммуностимулирующим эффектом. Хотя не была обнаружена токсичность экзополисахарида в отношении клеток рака, однако наблюдалась их гибель за счет активации иммунной системы [25]. В работе [44] Y.O. Kim et al. пришли к выводу, что иммуностимулирующая активность мицелиального эндополисахарида выше, чем экзополисахарида.

В более ранней работе Е.Г. Платоновой [67], водорастворимые полисахариды чаги отнесены к глюкозанам, на основании того, что свободные редуцирующие сахара в гидролизатах водных извлечений чаги представлены в основном глюкозой. Ею же [68] отмечено присутствие в некоторых случаях в составе полисахаридов незначительной доли пентоз: арабинозы и ксилозы. Т. Mizuno описал 21 вид полисахаридов в составе водных вытяжек чаги, отличающихся по своей структуре. Из них ксилогалтоглюканы обладают выраженными иммуномодулирующими свойствами [69].

X.-H. Zhong, L.-B. Wang и D.-Z. Sun обнаружили эффект ингибирования роста клеток карциномы легкого тритерпеноидом инотодиолом [66]. Антиканцерогенный эффект извлечений I. obliquus изучался также J. Burczyk et al. [28]; S.H. Lee, H.S. Hwang, J.W. Yun [51]; M.-J. Youn et al. [33; 57]; M. Nomura et al. [45]; M.J. Chung et al. [24]; Y. Nakajima et al. [32]; J.-R. Park et al. [59]. Анализируя данные работы касательно гепатомы, карциномы, лейкемии, рака толстой кишки и рака шейки матки, можно сделать вывод, что цитотоксичность, инактивация пролиферации раковых клеток, а также антимитотический (кариокластический), цитостатический и реверсивный эффекты достигаются через фрагментацию ДНК; ингибирование роста клеток, индукцию апоптоза и дифференцирования, являющихся следствием стимулирующей регуляции экспрессии проапоптотических белков и подавления антиапоптотических; приводят к уменьшению митотического индекса путем нарушения митоза, вызванного повышением числа клеток в метафазе. Y. Nakajima et al. [32] установили, что вещества фенольной природы, выделенные из метанольного экстракта чаги, обладают высокой цитотоксичностью в отношении нескольких видов раковых клеток и не токсичны в отношении нормальных, здоровых клеток. Из исследованных тритерпеноидов [32] только инотодиол приводил к ингибированию пролиферации.

Y. Song et al. [42] предложили использовать полисахариды гриба в качестве компонентов гетерогенных ингибиторов процесса роста раковых клеток, ими установлена оптимальная доза их применения 150 мг/мл. D.P. Won et al. также подтвердили, что при пероральном приеме полисахаридов гриба наблюдалось подавление роста меланомы [43].

Антигипергликемическую, антилипидпероксидантную и антиоксидантную активность извлечений и полисахаридов на мышах с аллоксановым диабетом и в норме установили J.-E. Sun et al. [26] и X. Xu et al. [27]. Как оказалось, полисахариды способны приводить к снижению уровня глюкозы в крови, уменьшать содержание неэтерифицированных (свободных) жирных кислот, общего холестерина, триглицеридов, холестерина липопротеидов низкой плотности, тогда как они увеличивают содержание холестерина липопротеидов высокой плотности, гликогена в печени и уровень инсулина у мышей с сахарным диабетом. В итоге гистолого-морфологическая экспертиза показала восстановление поврежденных панкреатических тканей. Антидиабетическую активность экстрактов чаги определили также J.-Y. Cha et al. [41] и Y.K. Park et al. [65]. Сведения о антиоксидантном эффекте извлечений I. obliquus также имеются у Y. Cui, D.-S. Kim, K.-C. Park [37]; Y.K. Park et al. [34]; S.S. Ham et al. [30]; H. Hu et al. [36]; W. Zheng et al. [55]; H.-K. Seo и S.-C. Lee [60]; Y. Nakajima, Y. Sato и T. Konishi [52]; M. Najafzadeh et al. [35]; H.S. Song et al. [38]; H.K. Ju et al. [39]. Из данных работ можно заключить следующее: наибольшую активность в борьбе со свободными радикалами, приводящими к повреждению молекул в клетке, и оксидантному стрессу, проявляет полифенольный комплекс, биосинтез которого в природных условиях значительно выше, чем при культивировании гриба в лабораторных условиях.

Антимутагенный эффект извлечений чаги, выраженный в форме ингибирования индуцированного мутагенеза Salmonella typhimurium, рассматривали S.-S. Ham et al. [29]. A.M. Шариков с соавторами показали, что метаболиты I. obliquus обладают выраженной бактерицидностью на примере штаммов Mycobacterium smegmatis [21] и Francisella tularensis [3].

В стоматологии В.М. Галченко с соавторами получили положительный эффект при лечении активной формы эрозии твердых тканей зуба сухим экстрактом чаги вместе с иммобилизованным магнитным гелем, что привело к полному исчезновению гиперестезии и стабилизации процесса деминерализации зубов [15]; Т.П. Зюбр с соавторами предложили технологию по созданию стоматологических фитопленок на основе сухого экстракта чаги для лечения инфекционных воспалительных заболеваний слизистых оболочек полости рта [19]. При лечении хронического рецидивирующего афтозного стоматита с применением пленок они обнаружили высокую скорость регенерации тканей и снижение срока лечения заболевания. 
Таким образом, можно заключить, что весь спектр изысканий лечебных свойств гриба чаги не может быть ограничен только существованием известных до настоящего времени рамок в форме углубления сведений о химических соединениях, входящих в состав извлечений из чаги, и исследованием их структуры по заранее откорректированным направлениям изучения действительных свойств и исчерпываться лишь репрезентированием их результатов, а способен открыть простор для научного поиска еще многим поколениям естествоиспытателей. В свою очередь новые знания химической структуры мицелия I. obliquus coздают предпосылки для более подробного изучения экологии и биологии этого гриба.

\section{Список литературы}

1. Бабицкая В.Г., Щерба В.В., Иконникова Н.В., Бисько Н.А., Митропольская Н.Ю., Билай В.Т. Антиокислительное и генопротекторное действие лекарственных базидиальных грибов Inonotus obliquus и Phellinus robustus // Успехи медицинской микологии: материалы III Всероссийского конгресса по медицинской микологии. М., 2005. Т. 5. С. 174-175.

2. Сбитнева Е.М. Гриб чага против 100 болезней. М., 2009. 64 с.

3. Шариков А.М., Пашенова Н.В., Нешумаев Д.А., Новицкий И.А. Исследование антибиотической активности гриба чаги в отношении возбудителя туляремии // Тихоокеанский медицинский журнал. 2010. №1. С. 64-65.

4. Сысоева М.А., Кузнецова О.Ю., Гамаюрова В.С., Суханов П.П., Зиятдинова Г.К., Будников Г.К. Исследование золя водных извлечений чаги. III. Влияние состава сырья на выход экстрактивных веществ водных извлечений чаги // Химия растительного сырья. 2004. №4. С. 29-34.

5. Сысоева М.А., Хабибрахманова В.Р., Гамаюрова В.С., Кудрявцева Л.А. Исследование золя водных извлечений чаги. VIII. Размеры частиц дисперсных фаз, образующихся при экстракции водных извлечений чаги органическими растворителями // Химия растительного сырья. 2008. №4. С. 129-132.

6. Сысоева М.А., Хабибрахманова В.Р., Гамаюрова В.С., Кудрявцева Л.А. Исследование золя водных извлечений чаги. IX. Определение размеров частиц дисперсной фазы золя извлечений чаги // Химия растительного сырья. 2008. №2. С. 75-80.

7. Сысоева М.А., Сысоева Е.В., Хабибрахманова В.Р., Гамаюрова В.С., Кудрявцева Л.А. Исследование золя водных извлечений чаги. Х. Протеолиз водного извлечения чаги ферментами желудочно-кишечного тракта // Химия растительного сырья. 2008. №2. С. 81-86.

8. Сысоева М.А., Хабибрахманова В.Р., Гамаюрова В.С., Тазеева А.Х. Исследование золя водных извлечений чаги. ХІ. Липиды водного извлечения чаги // Химия растительного сырья. 2008. №3. С. 119-122.

9. Сысоева М.А., Хабибрахманова В.Р., Гамаюрова В.С., Шаехова Н.К., Халитов Ф.Г. Исследование золя водных извлечений чаги. ХІІ. Осаждение дисперсной фазы водного извлечения чаги при изменении рН среды // Химия растительного сырья. 2009. №1. С. 131-135.

10. Сысоева М.А., Иванова Г.А., Гамаюрова В.С., Зиятдинова Г.К., Будников Г.К., Захарова Л.Я., Воронин М.А. Повышение актиоксидантной активности водных извлечений и меланинов чаги. І. Обработка водных извлечений чаги водными растворами гиперразветвленных полимеров // Химия растительного сырья. 2010. №2. C. $105-108$.

11. Сысоева М.А., Хабибрахманова В.Р., Гамаюрова В.С., Зиятдинова Г.К., Будников Г.К. Разделение водных извлечений чаги с использованием этилацетата. І. Антиоксидантная активность // Химия растительного сырья. 2007. №4. С. 101-104.

12. Сысоева М.А., Хабибрахманова В.Р., Минкин В.С., Гамаюрова В.С., Петрашень В.Е. Разделение водных извлечений чаги с использованием этилацетата. II. Парамагнитные свойства хромогенов чаги // Химия растительного сырья. 2007. №4. С. 105-109.

13. Сысоева М.А., Кузнецова О.Ю., Гамаюрова В.С., Суханов П.П., Зиятдинова Г.К., Будников Г.К. Разделение водных извлечений чаги с использованием этилацетата. III. Состав липидов, отделяемых из водного извлечения чаги этилацетатом // Химия растительного сырья. 2008. №1. С. 111-114.

14. Сысоева М.А., Хабибрахманова В.Р., Гамаюрова В.С., Кыямова Г.И. Разделение водных извлечений чаги с использованием этилацетата. IV. Состав веществ фенольной и терпеновой природы, отделяемых из водного извлечения чаги этилацетатом // Химия растительного сырья. 2009. №4. С. 117-122.

15. Галченко В.М., Артемьева И.А., Аксенова Г.И., Зюбр Т.П., Васильев И.Б. Результаты лечения активной формы эрозии твердых тканей зуба сухим экстрактом чаги и иммобилизованным магнитным гелем // Бюллетень ВСНЦ СО РАМН. 2006. №5. С. 50-51.

16. Саакян К.Р., Ващенко К.Ф., Дармограй Р.Э. Чага (черный березовый гриб). Аналитический обзор // Провизор. 2004. №16. C. 56-95.

17. Сысоева М.А., Юмаева Л.Р., Гамаюрова В.С., Зиятдинова Г.К., Будников Г.К., Халитов Ф.Г. Сравнительная характеристика антиоксидантной активности водных и спиртовых извлечений чаги // Химия растительного сырья. 2009. №2. С. 121-124.

18. Сысоева М.А., Хабибрахманова В.Р., Гамаюрова В.С. Исследование золя водных извлечений чаги. ХІІІ. Биологически активные вещества коллоидной системы, формируемой после удаления дисперсной фазы из водного извлечения чаги хлористоводородной кислотой // Химия растительного сырья. 2009. №3. С. 151-156. 
19. Зюбр Т.П., Васильев И.Б., Хорошутин П.П., Аксенова Г.И. Технология и стандартизация стоматологических фитопленок на основе чаги экстракта сухого // Биотехнология и биомедицинская инженерия: сб. тр. III Всерос. науч.-практ. конф. с междунар. участием. Курск, 2010. С. 270-272.

20. Шашкина М.Я., Шашкин П.Н., Сергеев А.В., Горяйнова Л.К. Чага, чаговит, чагалюкс в лечебной и профилактической практике. М., 2009. 66 с.

21. Шариков А.М. Гриб-чага Inonotus obliquus Pilat: антибиотическая активность метаболитов // Современные наукоемкие технологии. 2010. №8. С. 167-168.

22. Rhee S.J., Cho S.Y., Kim K.M., Cha D.-S., Park H.-J. A comparative study of analytical methods for alkali-soluble $\beta$-glucan in medicinal mushroom, Chaga (Inonotus obliquus) // LWT Food Science and Technology. 2008. Vol. 41, N3. Pp. 545-549.

23. Nakamura S., Iwami J., Matsuda H., Mizuno S., Yoshikawa M. Absolute stereostructures of inoterpenes A-F from sclerotia of Inonotus obliquus // Tetrahedron. 2009. Vol. 65, N12. Pp. 2443-2450.

24. Chung M.J., Chung C.-K., Jeong Y., Ham S.-S. Anticancer activity of subfractions containing pure compounds of Chaga mushroom (Inonotus obliquus) extract in human cancer cells and in Balbc/c mice bearing Sarcoma-180 cells // Nutrition Research and Practice. 2010. Vol. 4, N3. Pp. 177-182.

25. Kim Y.O., Park H.W., Kim J.H., Lee J.Y., Moon S.H, Shin C.S. Anti-cancer effect and structural characterization of endo-polysaccharide from cultivated mycelia of Inonotus obliquus // Life Sciences. 2006. Vol. 79, N1. Pp. 72-80.

26. Sun J.-E., Ao Z.-H., Lu Z.-M., Xu H.-Y., Zhang X.-M., Dou W.-F., Xu Z.-H. Antihyperglycemic and antilipidperoxidative effects of dry matter of culture broth of Inonotus obliquus in submerged culture on normal and alloxandiabetes mice // Journal of Ethnopharmacology. 2008. Vol. 118, N1. Pp. 7-13.

27. Xu X., Pang C., Yang C., Zheng Y., Xu H., Lu Z., Xu Z.-H. Antihyperglycemic and antilipidperoxidative effects of polysaccharides extracted from medicinal mushroom Chaga, Inonotus obliquus (Pers.: Fr.) Pilat (Aphyllophoromycetideae) on alloxan-diabetes mice // International Journal for Medicinal Mushrooms. 2010. Vol. 12, N3. Pp. $235-244$.

28. Burczyk J., Gawron A., Slotwinska M., Smietana B., Terminska K. Antimitotic activity of aqueous extracts of Inonotus obliquus // Boll Chim Farm. 1996. Vol. 135, N5. Pp. 306-309.

29. Ham S.-S., Kim S.-H., Moon S.-Y., Chung M.J., Cui C.-B., Han E.-K., Chung C.-K., Choe M. Antimutagenic effects of subfractions of Chaga mushroom (Inonotus obliquus) extract // Mutation Research/Genetic Toxicology and Environmental Mutagenesis. 2009. Vol. 672, N1. Pp. 55-59.

30. Ham S.S., Oh S.W, Kim Y.K., Shin K.S., Chung H.Y., Chung G.H. Antioxidant and genotoxic inhibition activity of ethanol extract from the Inonotus obliquus // Journal of the Korean Society of Food Science and Nutrition. 2003. Vol. 32, N7. Pp. 1071-1075.

31. Ayoub N., Lass D., Schultze W. Volatile constituents of the medicinal fungus Chaga Inonotus obliquus (Pers.: Fr.) Pilat (Aphyllophoromycetideae) // International Journal of Medicinal Mushrooms. 2009. Vol. 11, N1. Pp. 55-60.

32. Nakajima Y., Nishida H., Matsugo S., Konishi T. Cancer cell cytotoxicity of extracts and small phenolic compounds from Chaga [Inonotus obliquus (Persoon) Pilat] // Journal of Medicinal Food. 2009. Vol. 12, N3. Pp. 501-507.

33. Youn M.-J., Kim J.-K., Park S.-Y., Kim Y., Kim S.-J., Lee J.S., Chai K.Y., Kim H.-J., Cui M.-X., So H.S., Kim K.-Y., Park R. Chaga mushroom (Inonotus obliquus) induces G0/G1 arrest and apoptosis in human hepatoma HepG2 cells // World Journal of Gastroenterology. 2008. Vol. 14, N4. Pp. 511-517.

34. Park Y.K., Lee H.B., Jeon E.-J., Jung H.S., Kang M.-H. Chaga mushroom extract inhibits oxidative DNA damage in human lymphocytes as assessed by comet assay // BioFactors. 2004. Vol. 21, N1-4. Pp. 109-112.

35. Najafzadeh M., Reynolds P.D., Baumgartner A., Jerwood D., Anderson D. Chaga mushroom extract inhibits oxidative DNA damage in lymphocytes of patients with inflammatory bowel disease // BioFactors. 2007. Vol. 31, N3-4. Pp. 191-200.

36. Hu H., Zhang Z., Lei Z., Yang Y., Sugiura N. Comparative study of antioxidant activity and antiproliferative effect of hot water and ethanol extracts from the mushroom Inonotus obliquus // Journal of Bioscience and Bioengineering. 2009. Vol. 107, N1. Pp. 42-48.

37. Cui Y., Kim D.-S., Park K.-C. Antioxidant effect of Inonotus obliquus // Journal of Ethnopharmacology. 2005. Vol. 96, N1-2. Pp. 79-85.

38. Song H.S., Lee Y.J., Kim S.K., Moon K.Y., Moon W.K., Kim D.W., Kim Y.S. Downregulatory effect of AGI-1120 (N $\beta$-glucosidase inhibitor) and Chaga mushroom (Inonotus obliquus) on cellular NF-kB activation and their antioxidant activity // Korean Journal of Pharmacognosy. 2004. Vol. 35, N1. Pp. 92-97.

39. Ju H.K., Chung H.W., Hong S.-S., Park J.H., Lee J., Kwon S.W. Effect of steam treatment on soluble phenolic content and antioxidant activity of the Chaga mushroom (Inonotus obliquus) // Food Chemistry. 2010. Vol. 119, N2. Pp. 619-625.

40. Handa N., Yamada T., Tanaka R. An unusual lanostane-type triterpenoid, spiroinonotsuoxodiol and other triterpenoids from Inonotus obliquus // Phytocemistry. 2010. Vol. 71, N14-15. Pp. 1774-1779.

41. Cha J.-Y., Jun B.-S., Kim J.-W., Park S.-H., Lee C.-H., Cho Y.-S. Hypoglycemic effects of fermented Chaga mushroom (Inonotus obliquus) in the diabetic otsuka long-evans tokushima fatty (OLETF) rat // Food Science and Biotechnology. 2006. Vol. 15, N5. Pp. 739-745.

42. Song Y., Hui J., Kou W., Xin R., Jia F., Wang N., Hu F., Zhang H., Liu H. Identification of Inonotus obliquus and analysis of antioxidation and antitumor activities of polysaccharides // Curr. Microbiol. 2008. N57. Pp. 454-462.

43. Won D.P., Lee J.S., Kwon D.S., Lee K.E., Shin W.C., Hong E.K. Immunostimulating activity by polysaccharides isolated from fruiting body of Inonotus obliquus // Molecules and Cells. 2011. N31. Pp. 165-173. 
44. Kim Y.O., Han S.B., Lee H.W., Ahn H.J., Yoon Y.D., Jung J.K., Kim H.M., Shin C.S. Immuno-stimulating effect of the endo-polysaccharide produced by submerged culture of Inonotus obliquus // Life Sciences. 2005. Vol. 77, N19. Pp. 2438-2456.

45. Nomura M., Takahashi T., Uesugi A., Tanaka R., Kobayashi S. Inotodiol, a lanostane triterpenoid, from Inonotus obliquus inhibits cell proliferation through caspase-3-dependent apoptosis // Anticancer Research. 2008. Vol. 28, N5A. Pp. 2691-2696.

46. Kahlos K., Tikka V.H. Antifungal activity of cysteine, its effect on C-21 oxygenated ianosterol derivatives and other lipids in Inonotus obliquus, in vitro // Applied Microbiology and Biotechnology. 1994. N42. Pp. 385-390.

47. Kim Y.-R. Immunomodulatory activity of the water extract from medicinal mushroom Inonotus obliquus // Mycobiology. 2005. Vol. 33, N3. Pp. 158-162.

48. Lee J.H., Lee M.J. Effect of drying method on the moisture sorption isotherms for Inonotus obliquus mushroom // LWT Food Science and Technology. 2008. Vol. 41, N8. Pp. 1478-1484.

49. Lee M.J., Lee J.H. Moisture sorption isotherm characteristics of Chaga mushroom powder as influenced by particle size // Food Science and Bioechnology. 2007. Vol. 16, N1. Pp. 154-158.

50. Lee M.J., Seog E.J., Lee J.H. Physicochemical properties of Chaga (Inonotus obliquus) mushroom powder as influenced by drying methods // Journal of Food Science and Nutrition. 2007. Vol. 12, N1. Pp. 40-45.

51. Lee S.H., Hwang H.S., Yun J.W. Antitumor activity of water extract of a mushroom, Inonotus obliquus, against HT-29 human colon cancer cells // Phytotherapy Research. 2009. Vol. 23, N12. Pp. 1784-1789.

52. Nakajima Y., Sato Y., Konishi T. Antioxidant small phenolic ingredients in Inonotus obliquus (Persoon) Pilat (Chaga) // Chemical \& Pharmaceutical Bulletin. 2007. Vol. 55, N8. Pp. 1222-1226.

53. Lee I.-K., Kim Y.-S., Jang Y.-W., Jung J.-Y., Yun B.-S. New antioxidant polyphenols from the medicinal mushroom Inonotus obliquus // Bioorganic \& Medicinal Chemistry Letters. 2007. Vol. 17, N24. Pp. 6678-6681.

54. Zheng W., Zhang M., Zhao Y., Miao K., Jiang H. NMR-based metabonomic analysis on effect of light on production of antioxidant phenolic compounds in submerged cultures of Inonotus obliquus // Bioresource Technology. 2009. Vol. 100, N19. Pp. 4481-4487.

55. Zheng W., Zhao Y., Zhang M., Wei Z., Miao K., Sun W. Oxidative stress response of Inonotus obliquus induced by hydrogen peroxide // Medical Mycology. 2009. Vol. 47, N8. Pp. 814-823.

56. Kukulyanskaya T.A., Kurchenko N.V., Kurchenko V.P., Babitskaya V.G. Physicochemical properties of melanins produced by the sterile form of Inonotus obliquus («Chagi») in natural and cultivated fungus // Applied Biochemistry and Microbiology. 2002. Vol. 38, N1. Pp. 58-61.

57. Youn M.-J., Kim J.-K., Park S., Kim Y., Park C., Kim E.-S., Park K.-I., So H.S., Park R. Potential anticancer properties of the water extract of Inontus obliquus by induction of apoptosis in melanoma B16-F10 cells // Journal of Ethnopharmacology. 2009. Vol. 121, N2. Pp. 221-228.

58. Zheng W., Zhao Y., Zheng X., Liu Y., Pan S., Dai Y., Liu F. Production of antioxidant and antitumor metabolites by submerged cultures of Inonotus obliquus cocultured with Phellinus punctatus // Applied Microbiology and Biotechnology. 2011. N89. Pp. 157-167.

59. Park J.-R., Park J.-S., Jo E.-H., Hwang J.-W., Kim S.-J., Ra J.-C., Aruoma O.I., Lee Y.-S., Kang K.-S. Reversal of the TPA-induced inhibition of gap junctional intercellular communication by Chaga mushroom (Inonotus obliquus) extracts: Effects on MAP kinases // BioFactors. 2006. Vol. 27, N1-4. Pp. 147-155.

60. Seo H.-K., Lee S.-C. Antioxidant activity of subcritical water extracts from Chaga mushroom (Inonotus obliquus) // Separation Science and Technology. 2010. Vol. 45, N2. Pp. 198-203.

61. Shin Y., Tamai Y., Terazawa M. Chemical constituents of Inonotus obliquus II: a new triterpene, 21,24-cyclopentalanosta-3ß,21,25-triol-8-ene from sclerotium // Journal of Wood Science. 2001. N47. Pp. 313-316.

62. Zheng W.F., Liu T., Xiang X.Y., Gu Q. Sterol composition in field-grown and cultured mycelia of Inonotus obliquus // Yao Xue Xue Bao. 2007. Vol. 42, N7. Pp. 750-756.

63. Nakata T., Yamada T., Taji S., Ohishi H., Wada S., Tokuda H., Sakuma K., Tanaka R. Structure determination of inonotsuoxides A and B and in vivo anti-tumor promoting activity of inotodiol from the sclerotia of Inonotus obliquus // Bioorganic \& Medicinal Chemistry. 2007. Vol. 15, N1. Pp. 257-264.

64. Taji S., Yamada T., Tanaka R. Three new lanostane triterpenoids, inonotsutriols A, B and C, from Inonotus obliquus // Helvetica Chimica Acta. 2008. Vol. 91, N8. Pp. 1513-1524.

65. Park Y.K., Kim J.S., Jeon E.J., Kang M.H. The improvement of Chaga mushroom (Inonotus obliquus) extract supplementation on the blood glucose and cellular DNA damage in streptozotocin-induced diabetic rats // The Korean Journal of Nutrition. 2009. Vol. 42, N1. Pp. 5-13.

66. Zhong X.-H., Wang L.-B., Sun D.-Z. Effects of inotodiol extracts from Inonotus obliquus on proliferation cycle and apoptotic gene of human lung adenocarcinoma cell line A549 // Chin J Integr Med. 2011. N17 (3). Pp. 218-223.

67. Шиврина А.Н., Платонова Е.Г. О полисахаридных комплексах гуминоподобных соединений, образуемых дереворазрушающими грибами // Продукты биосинтеза высших грибов и их использование. М.; Л., 1966. С. 38-42.

68. Платонова Е.Г. Характеристика водорастворимых углеродных комплексов чаги и некоторых других трутовиков // Комплексное изучение физиологически активных веществ низших растений. М.; Л., 1961. С. 63-69.

69. Mizuno T. The extraction and development of antitumoractin polysaccharides from medicinal mushrooms in Japan // International Journal for Medicinal Mushrooms. 1999. N1. Pp. 9-29.

Поступило в редакиию 11 февраля 2012 2. 
Balandaykin M.E. TO THE QUESTION ON STUDYING OF CHEMICAL FRAME AND MEDICAL PROPERTIES OF INONOTUS OBLIQUUS (PERS.) PIL.

Ulyanovsk State University, ul. L. Tolstogo, 42, Ul'ianovsk, 432017, (Russia), e-mail: 131119892007@rambler.ru

The review of the new literary data, concerning problems widely discussed today in the scientific world on development of representations about character of a constitution and application of sterile nodes of mushroom Inonotus obliquus (Pers.) Pil., called polypore. (Van.) Nikol.

Keywords: immunomodulating, anticarcinogenic and antioxidant activity, Inonotus obliquus (Pers.) Pil. forma sterilis

\section{References}

1. Babitskaia V.G., Shcherba V.V., Ikonnikova N.V., Bis'ko N.A., Mitropol'skaia N.Iu., Bilai V.T. Uspekhi meditsinskoi mikologii: materialy III Vserossiiskogo kongressa po meditsinskoi mikologii. [Advances in medical mycology: Materials III All-Russian Congress of Medical Mycology]. Moscow, 2005, vol. 5, pp. 174-175. (in Russ.).

2. Sbitneva E.M. Grib chaga protiv 100 boleznei. [Chaga mushroom against the 100 diseases]. Moscow, 2009,64 p. (in Russ.).

3. Sharikov A.M., Pashenova N.V., Neshumaev D.A., Novitskii I.A. Tikhookeanskii meditsinskii zhurnal, 2010, no. 1, pp. 64-65. (in Russ.).

4. Sysoeva M.A., Kuznetsova O.Iu., Gamaiurova V.S., Sukhanov P.P., Ziiatdinova G.K., Budnikov G.K. Khimiia rastitel'nogo syria, 2004, no. 4, pp. 29-34. (in Russ.).

5. Sysoeva M.A., Khabibrakhmanova V.R., Gamaiurova V.S., Kudriavtseva L.A. Khimiia rastitel'nogo syr'ia, 2008, no. 4, pp. 129-132. (in Russ.).

6. Sysoeva M.A., Khabibrakhmanova V.R., Gamaiurova V.S., Kudriavtseva L.A. Khimiia rastitel'nogo syr'ia, 2008, no. 2, pp. 75-80. (in Russ.).

7. Sysoeva M.A., Sysoeva E.V., Khabibrakhmanova V.R., Gamaiurova V.S., Kudriavtseva L.A. Khimiia rastitel'nogo syr'ia, 2008, no. 2, pp. 81-86. (in Russ.).

8. Sysoeva M.A., Khabibrakhmanova V.R., Gamaiurova V.S., Tazeeva A.Kh. Khimiia rastitel'nogo syr'ia, 2008, no. 3, pp. 119-122. (in Russ.).

9. Sysoeva M.A., Khabibrakhmanova V.R., Gamaiurova V.S., Shaekhova N.K., Khalitov F.G. Khimiia rastitel'nogo syr'ia, 2009, no. 1, pp. 131-135. (in Russ.).

10. Sysoeva M.A., Ivanova G.A., Gamaiurova V.S., Ziiatdinova G.K., Budnikov G.K., Zakharova L. Ia., Voronin M.A. Khimiia rastitel'nogo syr'ia, 2010, no. 2, pp. 105-108. (in Russ.).

11. Sysoeva M.A., Khabibrakhmanova V.R., Gamaiurova V.S., Ziiatdinova G.K., Budnikov G.K. Khimiia rastitel'nogo syr'ia, 2007, no. 4, pp. 101-104. (in Russ.).

12. Sysoeva M.A., Khabibrakhmanova V.R., Minkin V.S., Gamaiurova V.S., Petrashen' V.E. Khimiia rastitel'nogo syr'ia, 2007, no. 4, pp. 105-109. (in Russ.).

13. Sysoeva M.A., Kuznetsova O.Iu., Gamaiurova V.S., Sukhanov P.P., Ziiatdinova G.K., Budnikov G.K. Khimiia rastitel'nogo syr'ia, 2008, no. 1, pp. 111-114. (in Russ.).

14. Sysoeva M.A., Khabibrakhmanova V.R., Gamaiurova V.S., Kyiamova G.I. Khimiia rastitel'nogo syria, 2009, no. 4, pp. 117-122. (in Russ.).

15. Galchenko V.M., Artem'eva I.A., Aksenova G.I., Ziubr T.P., Vasil'ev I.B. Biulleten' VSNTs SO RAMN, 2006, no. 5, pp. 50-51. (in Russ.).

16. Saakian K.R., Vashchenko K.F., Darmograi R.E. Provizor, 2004, no. 16, pp. 56-95. (in Russ.).

17. Sysoeva M.A., Iumaeva L.R., Gamaiurova V.S., Ziiatdinova G.K., Budnikov G.K., Khalitov F.G. Khimiia rastitel'nogo syr'ia, 2009, no. 2, pp. 121-124. (in Russ.).

18. Sysoeva M.A., Khabibrakhmanova V.R., Gamaiurova V.S. Khimiia rastitel'nogo syr'ia, 2009, no. 3, pp. $151-156$. (in Russ.).

19. Ziubr T.P., Vasil'ev I.B., Khoroshutin P.P., Aksenova G.I. Biotekhnologiia i biomeditsinskaia inzheneriia: sb. trudov III Vserossiiskoi nauchno-prakticheskoi konferentsii s mezhdunarodnom uchastiem. [Biotechnology and biomedical engineering: proceedings of the III All-Russian scientific-practical conference with international participation]. Kursk, 2010, pp. 270-272. (in Russ.).

20. Shashkina M.Ia., Shashkin P.N., Sergeev A.V., Goriainova L.K. Chaga, chagovit, chagaliuks v lechebnoi i profilakticheskoi praktike. [Chaga, chagovit, chagalyuks in curative and preventive practices.]. Moscow, 2009, 66 p. (in Russ.).

21. Sharikov A.M. Sovremennye naukoemkie tekhnologii, 2010, no. 8, pp. 167-168. (in Russ.).

22. Rhee S.J., Cho S.Y., Kim K.M., Cha D.-S., Park H.-J. LWT Food Science and Technology, 2008, vol. 41, no. 3, pp. 545-549.

23. Nakamura S., Iwami J., Matsuda H., Mizuno S., Yoshikawa M. Tetrahedron, 2009, vol. 65, no. 12, pp. $2443-2450$.

24. Chung M.J., Chung C.-K., Jeong Y., Ham S.-S. Nutrition Research and Practice, 2010, vol. 4, no. 3, pp. $177-182$.

25. Kim Y.O., Park H.W., Kim J.H., Lee J.Y., Moon S.H, Shin C.S. Life Sciences, 2006, vol. 79, no. 1, pp. $72-80$.

26. Sun J.-E., Ao Z.-H., Lu Z.-M., Xu H.-Y., Zhang X.-M., Dou W.-F., Xu Z.-H. Journal of Ethnopharmacology, 2008, vol. 118, no. 1, pp. 7-13.

27. Xu X., Pang C., Yang C., Zheng Y., Xu H., Lu Z., Xu Z.-H. International Journal for Medicinal Mushrooms, 2010, vol. 12 , no. 3, pp. 235-244. 
28. Burczyk J., Gawron A., Slotwinska M., Smietana B., Terminska K. Boll Chim Farm., 1996, vol. 135, no. 5, pp. $306-309$.

29. Ham S.-S., Kim S.-H., Moon S.-Y., Chung M.J., Cui C.-B., Han E.-K., Chung C.-K., Choe M. Mutation Research/Genetic Toxicology and Environmental Mutagenesis, 2009, vol. 672, no. 1, pp. 55-59.

30. Ham S.S., Oh S.W, Kim Y.K., Shin K.S., Chung H.Y., Chung G.H. Journal of the Korean Society of Food Science and Nutrition, 2003, vol. 32, no. 7, pp. 1071-1075.

31. Ayoub N., Lass D., Schultze W. International Journal of Medicinal Mushrooms, 2009, vol. 11, no. 1, pp. 55-60.

32. Nakajima Y., Nishida H., Matsugo S., Konishi T. Journal of Medicinal Food, 2009, vol. 12, no. 3, pp. 501-507.

33. Youn M.-J., Kim J.-K., Park S.-Y., Kim Y., Kim S.-J., Lee J.S., Chai K.Y., Kim H.-J., Cui M.-X., So H.S., Kim K.-Y., Park R. World Journal of Gastroenterology, 2008, vol. 14, no. 4, pp. 511-517.

34. Park Y.K., Lee H. B., Jeon E.-J., Jung H.S., Kang M.-H. BioFactors, 2004, vol. 21, no. 1-4, pp. 109-112.

35. Najafzadeh M., Reynolds P.D., Baumgartner A., Jerwood D., Anderson D. BioFactors, 2007, vol. 31, N3-4, pp. 191-200.

36. Hu H., Zhang Z., Lei Z., Yang Y., Sugiura N. Journal of Bioscience and Bioengineering, 2009, vol. 107, no. 1, pp. $42-48$.

37. Cui Y., Kim D.-S., Park K.-C. Journal of Ethnopharmacology, 2005, vol. 96, no. 1-2, pp. 79-85.

38. Song H.S., Lee Y.J., Kim S.K., Moon K.Y., Moon W.K., Kim D.W., Kim Y.S. Korean Journal of Pharmacognosy, 2004, vol. 35, no. 1, pp. 92-97.

39. Ju H.K., Chung H.W., Hong S.-S., Park J.H., Lee J., Kwon S.W. Food Chemistry, 2010, vol. 119, no. 2, pp. $619-625$.

40. Handa N., Yamada T., Tanaka R. Phytocemistry, 2010, vol. 71, no. 14-15, pp. 1774-1779.

41. Cha J.-Y., Jun B.-S., Kim J.-W., Park S.-H., Lee C.-H., Cho Y.-S. Food Science and Biotechnology, 2006, vol. 15, no. 5, pp. 739-745.

42. Song Y., Hui J., Kou W., Xin R., Jia F., Wang N., Hu F., Zhang H., Liu H. Curr. Microbiol., 2008, no. 57, pp. 454-462.

43. Won D.P., Lee J.S., Kwon D.S., Lee K.E., Shin W.C., Hong E.K. Molecules and Cells., 2011, no. 31, pp. $165-173$.

44. Kim Y.O., Han S.B., Lee H.W., Ahn H.J., Yoon Y.D., Jung J.K., Kim H.M., Shin C.S. Life Sciences, 2005, vol. 77, no. 19 , pp. 2438-2456.

45. Nomura M., Takahashi T., Uesugi A., Tanaka R., Kobayashi S. Anticancer Research, 2008, vol. 28, no. 5A, pp. 2691-2696.

46. Kahlos K., Tikka V.H. Applied Microbiology and Biotechnology, 1994, no. 42, pp. 385-390.

47. Kim Y.-R. Mycobiology, 2005, vol. 33, no. 3, pp. 158-162.

48. Lee J.H., Lee M.J. LWT Food Science and Technology, 2008, vol. 41, no. 8, pp. 1478-1484.

49. Lee M.J., Lee J.H. Food Science and Bioechnology, 2007, vol. 16, no. 1, pp. 154-158.

50. Lee M.J., Seog E.J., Lee J.H. Journal of Food Science and Nutrition, 2007, vol. 12, no. 1, pp. 40-45.

51. Lee S.H., Hwang H.S., Yun J.W. Phytotherapy Research, 2009, vol. 23, no. 12, pp. 1784-1789.

52. Nakajima Y., Sato Y., Konishi T. Chemical \& Pharmaceutical Bulletin, 2007, vol. 55, no. 8, pp. 1222-1226.

53. Lee I.-K., Kim Y.-S., Jang Y.-W., Jung J.-Y., Yun B.-S. Bioorganic \& Medicinal Chemistry Letters, 2007, vol. 17, no. 24, pp. 6678-6681.

54. Zheng W., Zhang M., Zhao Y., Miao K., Jiang H. Bioresource Technology, 2009, vol. 100, no. 19, pp. 4481-4487.

55. Zheng W., Zhao Y., Zhang M., Wei Z., Miao K., Sun W. Medical Mycology, 2009, vol. 47, no. 8, pp. 814-823.

56. Kukulyanskaya T.A., Kurchenko N.V., Kurchenko V.P., Babitskaya V.G. Applied Biochemistry and Microbiology, 2002, vol. 38, no. 1, pp. 58-61.

57. Youn M.-J., Kim J.-K., Park S., Kim Y., Park C., Kim E.-S., Park K.-I., So H.S., Park R. Journal of Ethnopharmacology, 2009, vol. 121, no. 2, pp. 221-228.

58. Zheng W., Zhao Y., Zheng X., Liu Y., Pan S., Dai Y., Liu F. Applied Microbiology and Biotechnology, 2011, no. 89, pp. 157-167.

59. Park J.-R., Park J.-S., Jo E.-H., Hwang J.-W., Kim S.-J., Ra J.-C., Aruoma O.I., Lee Y.-S., Kang K.-S. BioFactors, 2006, vol. 27, no. 1-4, pp. 147-155.

60. Seo H.-K., Lee S.-C. Separation Science and Technology, 2010, vol. 45, no. 2, pp. 198-203.

61. Shin Y., Tamai Y., Terazawa M. Journal of Wood Science, 2001, no. 47, pp. 313-316.

62. Zheng W.F., Liu T., Xiang X.Y., Gu Q. Yao Хие Хие Bao, 2007, vol. 42, no. 7, pp. 750-756.

63. Nakata T., Yamada T., Taji S., Ohishi H., Wada S., Tokuda H., Sakuma K., Tanaka R. Bioorganic \& Medicinal Chemistry, 2007, vol. 15, no. 1, pp. 257-264.

64. Taji S., Yamada T., Tanaka R. Helvetica Chimica Acta, 2008, vol. 91, no. 8, pp. 1513-1524.

65. Park Y.K., Kim J.S., Jeon E.J., Kang M.H. The Korean Journal of Nutrition, 2009, vol. 42, no. 1, pp. 5-13.

66. Zhong X.-H., Wang L.-B., Sun D.-Z. Chin. J. Integr. Med., 2011, no. 17(3), pp. 218-223.

67. Shivrina A.N., Platonova E.G. Produkty biosinteza vysshikh gribov $i$ ikh ispol'zovanie. [Products of biosynthesis of higher fungi and their use]. Moscow; Leningrad, 1966, pp. 38-42. (in Russ.).

68. Platonova E.G. Kompleksnoe izuchenie fiziologicheski aktivnykh veshchestv nizshikh rastenii. [Comprehensive study of physiologically active substances of lower plants]. Moscow; Leningrad, 1961, pp. 63-69. (in Russ.).

69. Mizuno T. International Journal for Medicinal Mushrooms, 1999, no. 1, pp. 9-29. 